\title{
Aerosol containment device for airway management of patients with COVID-19: a narrative review
}

\author{
Tomoyuki Saito ${ }^{1}$ Takashi Asai $^{1}$
}

Received: 25 September 2020 / Accepted: 9 November 2020 / Published online: 23 November 2020

(c) Japanese Society of Anesthesiologists 2020

\begin{abstract}
Severe acute respiratory syndrome-coronavirus-2 (SARS-CoV-2), which causes coronavirus disease 2019 (COVID-19), is highly contagious. To protect healthcare workers from infection during airway management, some expert recommendations and guidelines recommended wearing P2/N95 masks, goggles or glasses, glove, face-shields, and gowns as standard personal protective equipment (PPE). Nevertheless, several simulation studies have suggested that the standard PPE may not fully protect healthcare workers. Dr. Hsien Yung Lai introduced an acrylic box ("aerosol box") as a part of PPE during airway management. Since then, several companies and healthcare workers have made their own modified devices ("aerosol containment device"), and the use of such a device has spread worldwide, without being formally assessed for its effectiveness, efficacy and safety. Several simulation studies have indicated that "aerosol containment device" would make tracheal intubation more difficult. In addition, the device would prevent the spread of droplets from a patient, but may increase the risk of healthcare workers being exposed to a higher concentration of viral aerosols. Therefore, the current state of knowledge indicates that an "aerosol containment device" without vacuum mechanism has only limited efficacy in protecting healthcare workers from viral transmission.
\end{abstract}

Keywords Aerosol box · COVID-19 · Tracheal intubation

\section{Introduction}

Severe acute respiratory syndrome-coronavirus-2 (SARSCoV-2), which causes coronavirus disease 2019 (COVID19 ), is highly contagious [1-4]. A considerable number of healthcare workers are believed to have been infected while treating patients with COVID-19, and some died of acute respiratory distress syndrome worldwide [3, 4].

Transmission of SARS-CoV-2 is thought to be predominantly through respiratory droplets or secretions from coughing and gagging, and through a spread of aerosols (usually defined as small airborne particles $<5 \mu \mathrm{m}$ ) [5-7], in addition to direct contact with the patient or contaminated surfaces. Therefore, any procedures, which would increase the risk of

Tomoyuki Saito

s-tomo@dokkyomed.ac.jp

1 Department of Anesthesiology, Dokkyo Medical University Saitama Medical Center, 2-1-50 Minamikoshigaya, Koshigaya, Saitama 343-8555, Japan spreading viral aerosol from the patient's airway (so called "aerosol-generating procedures"), would put healthcare workers at a high risk of exposure to the virus [5]. Aerosolgenerating procedures include various anesthesia or intensive care techniques, such as tracheal intubation, tracheal extubation, non-invasive manual ventilation, tracheostomy, high-flow oxygen delivery, bronchoscopy, transesophageal echocardiography, and removal of oropharyngeal or tracheal secretion by suction.

To minimize the risk of cross-transmission of infection to healthcare workers and to another patients, expert recommendations and guidelines recommended that personal protective equipment (PPE: such as P2/N95 mask, goggles or glasses, gloves, face-shields, and gowns) be used while taking care of patients, such as while anesthetizing a patient or while transferring a patient between a ward and an operating room $[1,3,4,8-10]$. However, several simulation studies and expert recommendations suggested that the PPE may not fully prevent transmission of infection to healthcare workers, during airway management [11-13]. 
In March 2020, a Taiwanese anesthesiologist Hsien Yung Lai designed an acrylic box (called an "Aerosol Box") (Fig. 1), as a part of PPE during airway management [14]. In the next month, a simulation study has suggested that the aerosol box may protect healthcare worker from infection of COVID-19 [11]. This report has led to many companies and organizations to make a similar "intubation box" or "intubation tent", with their own versions. Front-line healthcare worker has also started to device their own methods of airway management, with the use of an "aerosol containment device" (as an aerosol box or drapes) [15-18]. Nevertheless, the efficacy and safety of this kind of box has never been clinically validated, and some problems associated with its use have been pointed out [11,19-21].

We consider that it is appropriate to describe the features and theoretical merits of the "aerosol containment device" in preventing viral infection, and then review the role of the device based on the current state of knowledge.

\section{Aerosol containment device}

The original "aerosol box" consists of a transparent acrylic box (40 $\mathrm{cm}$ in length, $50 \mathrm{~cm}$ in height, and $50 \mathrm{~cm}$ in width) with an opening on one side, allowing it to fit over the patient's head, neck and the chest, whereas the opposite side has two holes $(25 \mathrm{~cm}$ from the base and $10 \mathrm{~cm}$ from the side) through which a physician can insert his or her hands to perform airway management (Fig. 1).

Various modified boxes have been produced. For example, ports have been added to the side of the box so that the assistant can insert his or her hands to remove a stylet after tracheal intubation, or ports added to the top of the box for insertion of a bougie to intubate the trachea [16, 20]. Another modifications include a device or system to minimize spread of aerosol from the box, by attaching a plastic drape to the box, to spread the drape over the patient's chest, or by attaching a suction system to the box [22-24]. Some also have used transparent drapes, or plastic "balloons" to make an aerosol containment device [23-25].

\section{Efficacy of an aerosol containment device}

\section{Spread of droplets}

It is generally believed that one major route of viral transmission is through contact with viral droplets and aerosols emitted from the patient [3-7]. An "aerosol box", an "intubation box" or an "intubation tent" is designed to prevent
Fig. 1 The specification of the "Aerosol box", designed by Dr. Hsien Yung Lai (all units are in centimeters). The Dr. Lai states that "the box can be cheaply made using acrylic or transparent polycarbonate sheet at a cost of approximately US \$67 per unit. After each intubation, the box can be cleaned with $70 \%$ alcohol or bleach. It can then be reused for the next patient." (This work is licensed under a Creative Commons AttributionNon-Commercial 4.0 International License: https://sites .google.com/view/aerosolbox/ design?authuser $=0$ )

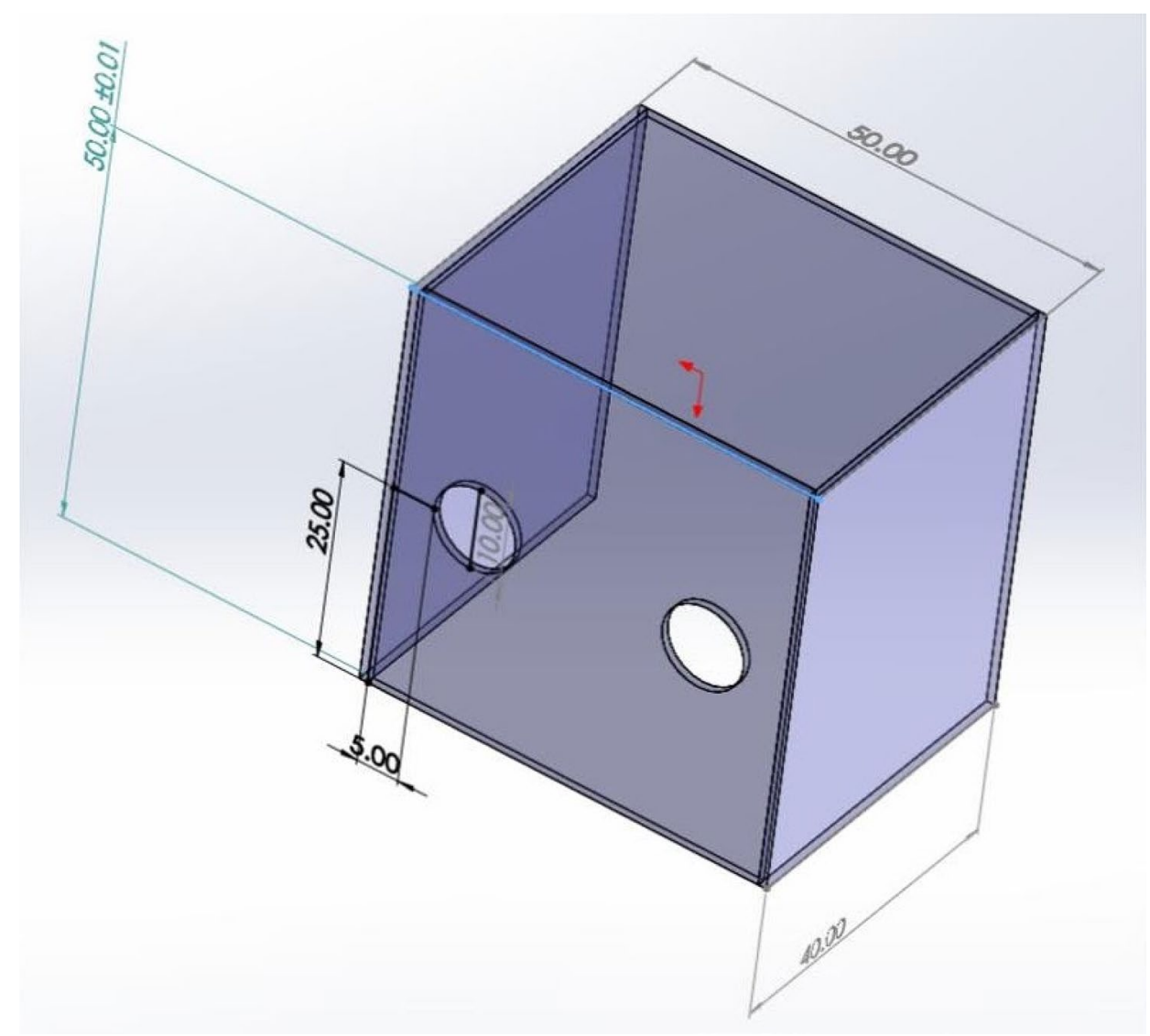


spread of aerosols or viral droplets, by making a shield between a patient and operators. Although there have been no studies which have shown that the use of an aerosol box decreases the incidence of viral infection, some simulation studies indicate that an aerosol box is likely to reduce viral infection.

For example, in one simulation study, coughing and aerosolization of droplets were simulated by spraying a dyed liquid from the manikin's mouth, during attempts at tracheal intubation [26]. Without the use of an aerosol box, the dye spread all over the operator's face shield, gown, arms, gloves, the neck and hair. In contrast, with the use of an aerosol box, a significantly lower amount of dye was detected on the operator [26]. Another simulation study using a manikin also has confirmed that an aerosol containing device made of a transparent plastic drapes effectively prevents spread of droplets during tracheal intubation and during extubation [27].

\section{Spread of aerosols}

Although an aerosol box would effectively protect a healthcare worker from being splashed by a patient's viral droplets, the box may not effectively prevent viral aerosols. In one study, airflow was analyzed (using a high-speed monochromatic camera), while a human volunteer was breathing normally, taking deep exhalations or coughing, with an aerosol box being placed over the volunteer' head and the upper body [28]. Substantial amounts of air moved out from open side of the box and into the operating room during coughing. In addition, air moves out of the box through the two holes of the box, during deep exhalation (but not during coughing) [28]. From this study, it is reasonable to conclude that, considerable amount of viral aerosol would move out of the box when the conventional aerosol box is used, and it would be necessary to seal the box, by placing a drape over the open side of the box as well as by attaching a sealing mechanism to the holes for insertion of operator's arms.

Another simulation study [24] also confirmed that viral aerosols may easily flow out of an aerosol box. In this study, saline was nebulized by a nebulizer which was held beneath the healthy volunteer's mouth, and airborne particles of different sizes were quantified, using an airborne particle counter positioned at the level of an operator's head $(75 \mathrm{~cm}$ above the simulated patient's head). The use of an aerosol box resulted in a marked increase, rather than decrease, in airborne particle exposure around the operator's head, compared with no device use. The authors speculated that this increase in the risk was that aerosols moving out of the box through the arm access holes in the aerosol box as a result of the Bernoulli principle.

The above study also quantified airborne particles at the level of an operator's head, while the operator was intubating the trachea, with either a sealed aerosol box, a transparent drape suspended vertically above the patient head, or a drape forming a horizonal tent above the patient's upper torso. Compared with no aerosol containment device, the use of these aerosol containment devices did not significantly affect the airborne particles [24].

To prevent the problem of viral aerosols to escape out of an aerosol containment device, some have produced a negative air-flow environment by applying suction mechanism [22-25]. In one report, a large cubic frame was created with polyvinylchloride tubes $(60 \times 60 \times 60 \mathrm{~cm})$, and clear plastic bags (400-800 L capacity) were used to enclose the space [23]. Another study also supports the findings that an aerosol box with suction mechanism effectively protects an operator from viral aerosol [24]. Simulated viral aerosol was created using an ultrasonic nebulizer, and the spread of aerosols was traced by applying ultraviolet light. With this system, no aerosols escaped from the aerosol containment device, and aerosols were successfully suctioned continuous negative airflow through vacuum mechanisms. Placing a highefficiency viral filter (which had $99.9999 \%$ viral filtration efficiency) between the suction port and the suction tubing would prevent contamination of the suction system [22].

From these simulation studies, it is reasonable to conclude that an aerosol box would minimize contaminated area through droplet as physical barrier, but aerosol during coughing or deep exhalation can move out from open side of the box. A vacuum filtering system attached viral clearance filter may decrease viral transmission through aerosols.

\section{Problems with the use of an aerosol containment device}

There have been no clinical studies comparing the effect of the use of an aerosol containment device on the ease of airway management, but several clinicians have reported that the use of the device makes airway management more difficult $[19,30]$. In addition, simulation studies have shown that the use of the device would make tracheal intubation more difficult. In one study, experienced staff attempted to intubate the trachea of a mannikin, using a Macintosh laryngoscope, with and without the use of an aerosol box [29]. The aerosol box made the viewing of the glottis significantly more difficult (significantly lowered the percentage of glottic opening (POGO) score), and significantly delayed time to intubate the trachea. The authors of the study stated that the difference in intubation time was approximately $3 \mathrm{~s}$, and thus clinically not meaningful, when an experienced anesthesiologist intubates the trachea in a normal airway condition [29].

In one simulation study on a videolaryngoscope (C-MAC, Karl Storz SE and Co, Tuttlingen, Germany) [20], time to intubate the trachea was compared between no aerosol box, 
an original aerosol box, and a modified box (which included ports to the side for the assistant's hands, and a port on top for insertion of a bougie to intubate the trachea). Intubation time was significantly longer with the use of either of the box than without the box, and the difference was clinically meaningful (difference of 30-40 s). In addition, a rigid aerosol box may cause damage to PPE and thus may lead to an increased risk of infection.

In another simulation study [21] on a videolaryngoscope (McGrath ${ }^{\circledR}$ (Aircraft Medical Ltd, Edinburgh, UK)), 20 inexperienced anesthesiologists with less than two months clinical anesthesia experience attempted to intubate the trachea of a mannikin, with and without the use of an aerosol box. The use of an aerosol box significantly prolonged intubation time, although the difference was small (3-4 s).

In third study on a videolaryngoscope (the McGrath ${ }$, or the Airway scope S200NK (Hoya, Tokyo, Japan), experienced staff attempted to intubate the trachea of a mannikin, with and without the use of an aerosol box [29]. This study indicated that an aerosol box would not significantly affect intubation time, when a videolaryngoscope is used by experienced staff.

From these simulation studies, it seems reasonable to conclude that the use of an "aerosol containment device" would delay intubation time and damage the PPE, and the delay may become clinically meaningful if tracheal intubation is found to be difficult, after induction of anesthesia.

\section{When to use?}

Aerosol-generating procedures are considered to have a greater risk of producing viral aerosols than coughing [5]. An aerosol containment device has been recommended to use during airway management after induction of general anesthesia, and the majority of studies have been performed on its efficacy during tracheal intubation. Nevertheless, tracheal intubation has been recommended to perform after rapid-sequence induction of anesthesia [4, 31], and thus in theory, coughing will not occur during attempts at tracheal intubation after induction of anesthesia.

An observational study has confirmed that the risk of the spread of viral droplets and aerosols is minimum during induction of anesthesia and during tracheal intubation [32]. This study, in which aerosol concentrations near the patient's mouth were measured, has shown that aerosol level was minimum during induction of anesthesia and tracheal intubation, which was 500-fold less than the average concentration recorded during coughing. In contrast, aerosol concentration was increased markedly during emergence from anesthesia, and the concentration was 15 -fold greater than that seen during tracheal intubation [32]. From these results, it is reasonable to conclude that an aerosol containment device has a much less use during induction of anesthesia than during emergence from anesthesia.

Several studies have proposed the use of an aerosol containment device, to prevent spread of droplets and aerosols during tracheal extubation $[25,27,33]$. The device includes a large clear plastic sheet, drape, and a balloon for aerosol protection with a suction system [25, 27, 33].

These methods are theoretically useful, but there may be risks of hypoxia, hypercapnia, or choking by the sheet. In addition, when re-intubation or manual ventilation using a facemask is required after tracheal extubation, such a rescue procedure may be hampered by the presence of the device. There have been no clinical studies assessing the degree of viral contamination around the patient's head after removal of the device. Lastly, such preventative measure may not be required at timing when tracheal extubation becomes possible, because the patient may frequently be no longer infectious about fortnight after infection [34].

\section{Videolaryngoscopy for tracheal intubation when aerosol box is used}

According to these simulation studies, aerosol box seems to delay intubation time. To minimize intubation time, some guidelines and expert recommendations recommend the use of a videolaryngoscope for the initial attempt $[3,4,31]$.

One simulation study has suggested that the use of a videolaryngoscope is more advantageous than the use of a Macintosh laryngoscope when tracheal intubation is attempted while an aerosol box was being placed [26]. This study assessed whether or not there was any difference in contamination of the operator by patient's viral aerosols between a videolaryngoscope and a Macintosh laryngoscope [26]. Coughing of droplets and aerosols were simulated by spraying a dyed liquid from the patient's mouth, during attempts at tracheal intubation. Contamination of the operator by the dye was significantly lower when a videolaryngoscope was used than when a Macintosh laryngoscope was used [26]. No dye was found on any part of outside the box including operator's gown, face shield, neck, and hair when used a videolaryngoscope was used for tracheal intubation through the aerosol box.

The efficacy of tracheal intubation may differ considerably between different videolaryngoscopes [35]. Some theoretical requirements for a suitable videolaryngoscope include that the success rate of tracheal intubation is high even in patients with difficult airways, intubation time is short, no introducer, such as a stylet or a gum elastic bougie, is required (so that no assistant is required to remove the introducer after tracheal intubation), and the device can be disposed or appropriately disinfected after use. 
One study compared the efficacy of four videolaryngoscopes (the Airtraq ${ }^{\circledR}$ (Prodol, Vizcaya, Spain), the Airwayscope ${ }^{\circledR}$ S-100 (Hoya, Tokyo, Japan), the Kingvison ${ }^{\circledR}$ (Ambu, Copenhagen, Denmark), the McGrath ${ }^{\circledR}$, with a Macintosh laryngoscope, in intubation time, in a manikin, with an aerosol box [36]. Among these videolaryngoscopes, the Airwayscope ${ }^{\circledR}$ and the McGrath $₫$ were more effective. In addition, for the Airwayscope ${ }^{\circledR}$, a stylet is not required, and thus a heat and moisture exchanger as well as a breathing system can be kept connected during tracheal intubation. Once a tube is inserted to the trachea and its cuff inflated, oxygen can be given immediately [37].

From these studies, it is reasonable to conclude that the use of an "aerosol containment device" may make tracheal intubation more difficult, and may delay oxygenation after successful tracheal intubation, and thus a suitable videolaryngoscope should be used from the first attempt at intubation.

\section{Conclusions}

Although limited, several simulation studies have indicated that an "aerosol containment device" may be useful to prevent the spread of viral droplets from a patient during aerosol-generating procedures, but it may increase the risk of healthcare workers being exposed to a higher concentration of viral aerosols. A vacuum filtering system attached to the "aerosol containment device" would effectively minimize the spread of aerosols. Therefore, the current state of knowledge indicates that an "aerosol containment device" without vacuum mechanism has only limited efficacy in protecting healthcare workers from viral transmission.

If an "aerosol containment device" with a vacuum mechanism is to be used, tracheal intubation should be performed by an experienced operator who has made enough experience with the use of the device in a manikin, and a suitable videolaryngoscope such as the Airwayscope ${ }^{\circledR}$ should be used.

Acknowledgements We thank the staff of the Department of Anesthesiology, Dokkyo Medical University Saitama medical center, for their contribution to this study.

Author contributions Both authors designed, described and edited the manuscript, and approved its final version.

\section{Compliance with ethical standards}

Conflict of interest All authors declare that they have no conflict of interest.

\section{References}

1. Yamakage M. Anesthesia in the times of COVID-19. J Anesth. 2020. https://doi.org/10.1007/s00540-020-02798-4 ((Advance Access published on May 25, 2020)).

2. Asai T, O'Sullivan EP, Hemmings HC Jr. A Special issue on respiration and the airway: critical topics at a challenging time. Br J Anaesth. 2020;125:1-4.

3. Peng PWH, Ho P-L, Hota SS. Outbreak of a new coronavirus: what anaesthetists should know. Br J Anaesth. 2020;124:497-501.

4. Cook TM, El-Boghdadly K, McGuire B, McNarry AF, Patel A, Higgs A. Consensus guidelines for managing the airway in patients with COVID-19: guidelines from the Difficult Airway Society, the Association of Anaesthetists the Intensive Care Society, the Faculty of Intensive Care Medicine and the Royal College of Anaesthetists. Anaesthesia. 2020;75:785-99.

5. Tran K, Cimon K, Severn M, Pessoa-Silva CL, Conly J. Aerosol generating procedures and risk of transmission of acute respiratory infections to healthcare workers: a systematic review. PLoS ONE. 2012;7:e35797.

6. van Doremalen N, Bushmaker T, Morris DH, Holbrook MG, Gamble A, Williamson BN, Tamin A, Harcourt JL, Thornburg NJ, Gerber SI, Lloyd-Smith JO, Wit E, Munster VL. Aerosol and surface stability of SARS-CoV-2 as compared with SARSCoV-1. N Engl J Med. 2020;382:1564-7.

7. Cook TM. Personal protective equipment during the COVID-19 pandemic: a reply. Anaesthesia. 2020;75:1121-2.

8. Cheung JC, Ho LT, Cheng JV, Cham EYK, Lam KN. Staff safety during emergency airway management for COVID-19 in Hong Kong. Lancet Respir Med. 2020;8:e19.

9. Brewster D, Chrimes N, Do T, Fraser K, Groombridge CJ, Higgs A, Humar MJ, Leeuwenburg TJ, McGloughlin S, Newman FG, Nickson CP, Rehak A, Vokes D, Gatward JJ. Consensus statement: safe Airway Society principles of airway management and tracheal intubation specific to the COVID-19 adult patient group. Med J Aust. 2020;212:472-81.

10. Zuo MZ, Huang YG, Ma WH, Xue Z, Zhang J, Gong Y, Che L. Expert recommendations for tracheal intubation in critically ill patients with novel coronavirus disease 2019. Chin Med Sci J. 2020;35:105-9.

11. Canelli R, Connor CW, Gonzalez M, Nozari A, Ortega R. Barrier enclosure during endotracheal intubation. N Engl J Med. 2020;382:1957-8.

12. Feldman O, Meir M, Shavit D, Idelman R, Shavit I. Exposure to a surrogate measure of contamination from simulated patients by emergency department personnel wearing personal protective equipment. JAMA. 2020;323:2091-3.

13. Weissman DN, de Perio MA, Radonovich LJ. COVID-19 and risks posed to personnel during endotracheal intubation. JAMA. 2020;323:2027-8.

14. Everington K. Taiwanese doctor invents device to protect US doctors against coronavirus. Taiwan News. https://www.taiwa nnews.com.tw/en/news/3902435. Accessed 18 Aug 2020.

15. Moraga FAL, Moraga EL, Moraga FL, Moraga FL, Gonzalez AJ, Celaya JMI, Galegos JAO, Espinoza JAB. Aerosol box, an operating room security measure in COVID-19. World J Surg. 2020;44:2049-50.

16. Malik JS, Jenner C, Ward PA. Maximising application of the aerosol box in protecting healthcare workers during the COVID19 pandemic. Anaesthesia. 2020;75:974-5.

17. Brown S, Patrao F, Verma S, Lean A, Flack S, Polaner D. Barrier system for airway management for COVID-19 patients. Anesth Analg. 2020;131:e34-5. 
18. Au Yong PS, Chen X. Reducing droplet spread during airway manipulation: lessons from the COVID-19 pandemic in Singapore. Br J Anaesth. 2020;125:e176-8.

19. Kearsley R. Intubation boxes for managing the airway in patients with COVID-19. Anaesthesia. 2020;75:969.

20. Begley JL, Lavery KE, Nickson CP, Brewster DJ. The aerosol box for intubation in coronavirus disease 2019 patients: an in-situ simulation crossover study. Anaesthesia. 2020;75:1014-21.

21. Saito T, Turumachi N, Okuda Y. Aerosol box for tracheal intubation by a junior operator in patients with COVID-19. Minerva Anestesiol. 2020. https://doi.org/10.23736/S0375-9393.20.14979 -4 ((Advance Access published on Aug 5)).

22. Hellman S, Chen GH, Irie T. Rapid clearing of aerosol in an intubation box by vacuum filtration. Br J Anaesth. 2020;125:e296-9.

23. Cubillos JA, Querney J, Rankin A, Moore J, Armstrong K. A multipurpose portable negative air flow isolation chamber for aerosol-generating procedures during the COVID-19 pandemic. Br J Anaesth. 2020;125:e179-81.

24. Simpson JP, Wong DN, Verco L, Carter R, Dzidowski M, Chan PY. Measurement of airborne particle exposure during simulated tracheal intubation using various proposed aerosol containment devices during the COVID-19 pandemic. Anaesthesia. 2020. https ://doi.org/10.1111/anae.15188 ((Advanced access published on Jun 19)).

25. Hirose K, Uchida K, Umezu S. Airtight, flexible, disposable barrier for extubation. J Anesth. 2020;34:798-9.

26. Yang SS, Zhang M, Chong JJR. Comparison of three tracheal intubation methods for reducing droplet spread for use in COVID19 patients. Br J Anaesth. 2020;125:e190-1.

27. Matava CT, Yu J, Denning S. Clear plastic drapes may be effective at limiting aerosolization and droplet spray during extubation: implications for COVID-19. Can J Anaesth. 2020;67:902-4.

28. Dalli J, Khan MF, Nolan K, Cahill RA. Evaluating intubation boxes for airway management. Br J Anaesth. 2020;125:e293-5.

29. Wakabayashi R, Ishida T, Yamada T, Kawamata M. Effect of an aerosol box on tracheal intubation difficulty. J Anesth. 2020;34:790-3.
30. Gould CL, Alexander PDG, Allen CN, McGrath BA, Shelton CL. Protecting staff and patients during airway management in the COVID-19 pandemic: are intubation boxes safe? Br J Anaesth. 2020;125:e292-3.

31. Yao W, Wang T, Jiang B, Gao F, Wang L, Zheng H, Xiao W, Yao S, Mei W, Chen X, Luo A, Sun L, Cook T, Behringer E, Huitink JM, Wong DT, F ML, McNarry AF, McGuire B, Higgs A, Shah A, Patel A, Zuo M, Xue Z, Zhang LM, Li W, Wang Y, Hagberg C, Sullivan EP, Fleisher LA, Wei H. Emergency tracheal intubation in 202 patients with COVID-19 in Wuhan, China: lessons learnt and international expert recommendations. Br J Anaesth. 2020;125:e28-37.

32. Brown J, Gregson FKA, Shrimpton A, Cook TM, Bzdek BR, Reid JP, Pickering AE. A quantitative evaluation of aerosol generation during tracheal intubation and extubation. Anaesthesia. 2020. https://doi.org/10.1111/anae.15292 ((Advance access published on Oct 6)).

33. Patino Montoya M, Chitilian HV. Extubation barrier drape to minimise droplet spread. Br J Anaesth. 2020;125:e195-6.

34. Wölfel R, Corman VM, Guggemos W, Seilmaier M, Zange S, Müller MA, Niemeyer D, Jones TC, Vollmar P, Rothe C, Hoelscher M, Bleicker T, Brünink S, Schneider J, Ehmann R, Zwirglmaier K, Drosten C, Wendtner C. Virological assessment of hospitalized patients with COVID-2019. Nature. 2020;581:465-9.

35. Asai T. Videolaryngoscopes: do they truly have roles in difficult airways? Anesthesiology. 2012;116:515-7.

36. Saito T, Taguchi A, Asai T. Videolaryngoscopy for tracheal intubation in patients with COVID-19. Br J Anaesth. 2020;125:e284-6.

37. Saito T, Asai T. Instant oxygenation after tracheal intubation in patients with COVID-19. J Anesth. 2020;34:801.

Publisher's Note Springer Nature remains neutral with regard to jurisdictional claims in published maps and institutional affiliations. 